\title{
ESTADO GERAL DE SAÚDE DOS PROFISSIONAIS ENFERMEIROS DE UM HOSPITAL DE REFERÊNCIA DA REGIÃO NORTE E NOROESTE DO ESTADO DO RIO DE JANEIRO
}

\author{
Lucas A. Freire ${ }^{3}$, Thayane C. S. Freire ${ }^{3}$, Nina A. F. Pereira ${ }^{3}$, Carolina M. Santos ${ }^{2}$ \& Thaís A. C. \\ Palermo $^{12}$
}

(1) Professora orientadora do curso Enfermagem do ISECENSA- Institutos Superiores de Ensino do CENSA, Rua Salvador Correa, 139, Centro,

Campos dos Goytacazes, RJ, Brasil; (2) Pesquisadora do Laboratório de Estudos em Saúde Pública - (NUPENSP/ISECENSA); (3) Acadêmico (a) do curso de Enfermagem do ISECENSA.

O cuidado de enfermagem é exercido por profissionais de diferentes níveis de formação, caracterizado pelo desenvolvimento de processos de trabalho específicos e pela necessidade de assistência constante ao paciente, que exige a implementação de turnos ininterruptos, de revezamento, plantões de final de semana, noturnos e feriados. Nessas condições, os trabalhadores de enfermagem têm se submetido a diferentes cargas de trabalho geradoras de processos de desgaste físico, interferindo diretamente em sua saúde como na qualidade da assistência prestada. Neste contexto, o enfermeiro além de prestar assistência, desempenha ainda a função de coordenar sua equipe. Por isso, o estado geral de saúde é relevante para a construção multidimensional da saúde, trata-se de um indicador subjetivo que correlaciona componentes físicos e emocionais, além de questões do bem-estar e da satisfação com a vida social e profissional. Sendo assim, o objetivo deste estudo é: discutir sobre o estado geral de saúde dos enfermeiros no contexto atual da enfermagem. Este estudo foi realizado através do método de revisão integrativa da literatura, com análise de 21 publicações científicas, disponíveis em base de dados online SCIELO E BVS, publicados nos últimos 10 anos (2008-2018). Utilizou-se os seguintes DeCS: Saúde do Trabalhador; Enfermagem; Qualidade de Vida. Para a organização e escolha dos achados, a pré-seleção dos artigos foram realizadas através da leitura do título e resumo. Há a constatação de que a enfermagem, enquanto trabalho inserido no setor hospitalar, na prestação de serviços de assistência à saúde, sofre impactos biopsicossociais, que são constatados pelas más condições de trabalho, o que é inquestionável e comprovado pelo adoecimento dos trabalhadores, cujo adoecimento não ganha a transparência e a visibilidade necessárias nas estatísticas oficiais. Portanto, concluise que uma atenção a sua própria saúde se faz necessária, considerando que, além de um bom estado geral de saúde para garantir uma vida saudável, bem como recomendado a todo indivíduo, deve haver uma preparação e condições biopsicossociais satisfatórias para o exercício de suas atribuições laborais extremamente complexas.

Palavras-chave: Saúde do Trabalhador; Enfermagem; Qualidade de Vida. 